UC-34

Reporting Date: Moy 1974

Issued: July 1974

\title{
A New Technique for Nonlinear Optical Problems
}

by

C. James Elliott

Dale B. Henderson 
This report was prepened as an account of work sposered by the United States Government. Neither the United States nor the United Stutes Atomic Energy Commiscion, nor any of their employos, nor any of their contractors, aubcontractors, or their employees, makes any werrenty, expres or implied, or esumes eny lopl lisbility or responsibility for the accuracy. completeness or usefuliness of any information, spperatus, product or process disclosed, of represents that its use would not infringe privately owned rights.

In the interest of prompt distribution, this LAMS report was not edited by the Tochnical information staff.

Printed in the United States of America. Available from National Technical Information Service

U.S. Department of Commerce 5285 Port Royal Road Springtield, Virginia 22151 Price: Printed Copy \$4.CO Microfiche \$1.45 


\title{
A SEN TECHIQUE FOR HONLINEAR OPTICAL FROBLEIS
}

by

C. Jawes ElJ lott and Dale B. Henderson

\begin{abstract}
The propagation of high intensity or high poier lasex pulses presents a variety of nonlipear optical prowlers requiring self-conalstent study. Our method treats arbitrary three-disensional problems vith unlielted phase discortion and 18 stallar to the particle-1n-cell (PIC) methods of hydrodynamics and electromagnet1c plasma simulation. Our numerical algorithm is based on Yaxyell's equations and is applied to laser-fuston reactor and laser atplifier problems.
\end{abstract}

\section{INTRODUCTION}

The propagation of high intensity or high power laser pulses presents a varlety of nonlinear opt1cal problems requiring belf-consistent study. The common element of these problems is that the optical properties of the medius are changed on a time scale comparable to the length of the pulse. These medium changes may be due to the pulse intensity, such as the nonlinear refractive index leading to selffocusing; to the history of the pulse intensity, such as Ionization; or they may be indtiated by the pulse, such as photochemistry. Previous methods 1 have allowed computer simulations of two-dimensional (typlcally axisymmetric) problems involving limited phase distortion. The present (new) method allows arbitrary three-dimensional problems with unlifited distortion. The price pald for the generality (within the frametork of state-of-the-art computers) is a 1imited capability for diffraction or interference phenomena so that the present method complements rather than replaces the others.

Our method may be viewed as a wedding of particle-1n-cell (PIC) wethods of hydrodynamics ${ }^{2}$ and electromagne: ic plasma stmulation ${ }^{3}$ wth ray tracing techniques. We represent the optical field by discrete entities which for lack of a better term we refer to as corpuscles, these being analogous to the particies of the PIC cethod. Each of these corpuscles woves in a trajectory which is also andiogous to a ray of the ray tracing technique. The ray tractng analogy breaks dorn, horrever, because corpuscle trajectorles are not streamlines; trafectories which are traced out by early corpuscles in the pulse do not serve as trajectorles for the later ones.

We w11 refer to our new Eethod as the corpuscle-1n-media (CIM) treatcent. Iike the rethods upon which CMi is based, CIM Involves ideas which are eas1ly cotivated. Following an 1ntuftive presentation we derive the relevant equations fros Maxwell's equations. We then discuss tro different applications. The first of these requires the un1imited phase distortions and the second requires full three-dimensional geocetry.

\section{CIM LETHOD}

The basfc idea is quite sieple. The 1ight pulse is considersd as a swart of finite corpuscles, finite in number. Each corpuscle has a position, a velocity, and an e.jergy. It also has a phase (proper time) and polarization, if required. The rediun through which the corpuscles move is sioflicrly thought of as being broken into a collection of 
flaite volumes or cells. By sumbing the energy of corpuscles vithin a given cell we compute the intensity, by ceans of which the light pulse acts on the medium.

The computer code follows the problad in twopart, finite cime steps. First the Ewarm of corpuscles are advanced frow their old to nes positions according to their velocities. Simultaneously their velocities are advanced (with changes wostly due to refraction) according to the (twe-fixed) grid of medium properties. Also the corpuscle energles are advanced according to the mediur's gatn and/or absorption. During the second part of a tine step the medium properties are updated according to the (time-fixed) optical intensities computea fros tia corpuscle positions and energies.

The differencing of the equations depends on the application. Generally it is best to difference the equations for the position and velocity of the corpuscles to second-order accuracy In the time step, an explicit half-step/full-step Runge-Kutta method belng one way to do this. When Ifnear or saturable gain (or absorption) is strong cospared to the nonIInear refractive index effects, closed exponential forms for the corpuscle weight or energy allow larger time steps. In assigning intensities onto the medium grid in computing medium forces back to the corpuscles we use the area- or volume-reighting Ideas of hydrodynamies or plasma simulation ${ }^{3}$ PIC. Unlike the fluid problems, the swarm of corpuscles Is finite in extent with easily described overall motlons. Th1s feature allows use of a "moving windos" concept so that only part of the medium needs to be represented in computer nemory at any one time. The physical scale way also be contracted or expanded between time steps in order to maintain zesolution and numerical significance as the pulae moves toward or away from a focus.

Unlike most PIC problems, the very small relative motions between corpuscles cause the corpuscles to stay pretty much as orginally orcered.

Th1s characterist1c makes useful differently welghted corpuscles in different (original) iocations and gives an Important gain in the numerical significance possible with a given number of particles representIng a nonuniform pulse.
Because we are following the trotion of fintte corpuscles, there 18 scoe teaptation to describe orn rechnique as "ray-tractog." As already discucsed, this is a poor description because a "roy" is now generally thought of as a stremilne, along which a stream of corpuscles $f 10 w$. In unsteady caseb, how ever, corpuscla trajectorfes are not btremines and the scesdy ray trajectory dees not extat. 4

\section{FERIFICATION}

We begin with the Fourler decosposed wove equazion at frequency $\omega$, negleccing variations of the agaetic subceptlbility wich we take to be unity

$$
\nabla^{2} \underline{E}-\underline{Q} \underline{Q} \cdot \underline{E}=\epsilon k_{0}^{2} \underline{E} .
$$

Here $c$ is the dielectric conscant, $k_{0}$ is the free space vave number $\mathrm{a} / \mathrm{c}$, and the full electric field assoclated with this frequency cosfonent is

$$
E_{\text {full }}=\operatorname{Re}\{\underline{\underline{E}} \operatorname{erp}(10 t)\}
$$

Thts haraonic decomposition lo jalld even when nonIInear interactions are inportant providing that curing the time step in vhich ve propagate the pulse, the local Inearization is justified. Indeed it is chis requirenent which serves to deteraine the tife step we use.

Uaing $\underline{\nabla} \cdot E \underline{E}=0$ ve ay vrite Eq. (1) as

$$
\nabla^{2} \underline{E}+\underline{\nabla}[\underline{E} \cdot \nabla \ln \varepsilon]=\varepsilon k_{0}^{2} \underline{E} \text {. }
$$

Using the phase amplitude representation of $\underline{E}$,

$$
\underline{E}(\underline{x}, t)=\underline{e}(\underline{x}) \exp \left[1 k_{0} L(\underline{x})\right] \text {, }
$$

where $e$ is the real vector axplitude and $L(x)$ is the optical path length, we way take advantage of the grall paraneters $\left|\nabla E_{1}\right| /\left(k_{0} z_{1}\right)$ and $|\nabla \in| /\left(k_{0} \varepsilon\right)$ (where $E_{1}$ is any conponent of E), by expanding Eq. (3) to firat order in $k_{0}^{-1}$. We get the geouetrical optica equation 5

$$
\begin{aligned}
& \left(\varepsilon_{R}+1 \varepsilon_{I}-(\nabla L)^{2}\right) \underline{e}+\left(1 k_{0}\right)^{-1}\left[-\nabla^{2} L \underline{e}\right. \\
& \left.-\underline{e} \cdot \underline{\nabla} \ln \left(\varepsilon_{R}+1 \varepsilon_{I}\right) \underline{\nabla}-2 \nabla L \cdot \underline{\nabla}\right]-0 .
\end{aligned}
$$


In problems of interest to us, we tay gimplify Eq. (5) by takiag further advantage of several 8mall parameters. Firat, the Inaginary part of the

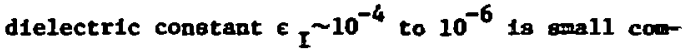
pared to the real part $\cdot \varepsilon_{R} \sim 1$. Secondly, as noted gbove $\nabla \ell n \varepsilon_{\mathrm{R}} 18$ emall compared to $\mathrm{k}_{0}$. We incorporate these approximations in the real and imaginary parts of Eq. (5) as follows

$$
(V L)^{2}-\sqrt{\epsilon_{R}}
$$

and

$$
\begin{aligned}
& \left(k_{0} \varepsilon_{I}+\nabla^{2} L\right) \underline{e}+\underline{e} \cdot \nabla k n \sqrt{\varepsilon_{R}} \nabla \\
& +2 \underline{\nabla} \cdot \underline{\nabla e}=0 .
\end{aligned}
$$

The imazinary part, Eq. (7), may be simplified by the definition

$$
8=\varepsilon_{I} k_{0} / \sqrt{\varepsilon_{R}}
$$

and substitution of $\mathrm{Eq}$. (6) to give

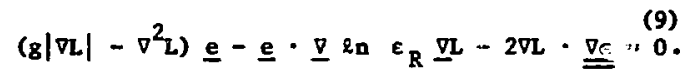

By taking the Bcalar product of Eq. (9) with e and noting $e \cdot v L=0$

$$
\underline{\nabla} \cdot\left(\mathrm{e}^{2} \underline{\nabla}\right)=g \mathrm{e}^{2}|\nabla L| .
$$

That' $g$ introduced in Eq. (8) Is the intensity gain coefficient follows from Eq. (18) below.

The phase speed $v$ in our medium is afmply

$$
\begin{aligned}
v & =\omega / k=c k_{0} /\left(|\nabla L| k_{0}\right) \\
& =c /|\eta|=c / \sqrt{\varepsilon_{R}} .
\end{aligned}
$$

The characteristics have this speed and are in the direction of VL:

$$
\underline{v}=\left(\bar{L} / \sqrt{\varepsilon_{R}}\right) v \text {. }
$$

In order to find the acceleration of the characterIstics we need only operate on $\underline{v}$ with the convactive derivative $d / d t=\underline{v} \cdot \underline{\underline{v}}$,

$$
\begin{aligned}
\underline{a}(\underline{v}, \underline{x}) & =\underline{d v} / d \tau=(\underline{v} \cdot \underline{v}) \underline{v} \\
& =\left(c^{c_{R}^{-1}} \underline{\underline{v}} \cdot \underline{\nabla}\right)\left(c_{R}^{\varepsilon_{R}^{-1}} \underline{\underline{v}}\right) \\
& =\left(1 / 2 \underline{v}^{2} \underline{\underline{I}}-\underline{\underline{v}}\right) \cdot \nabla \ln \epsilon_{R}
\end{aligned}
$$

Equation (13) 16 the eçuefic: =0 ja s=ivet for ze-

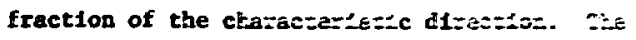
propagetion of the opticai ieagtt I is $x$ :ap?

$$
d \mathbf{L} / \mathrm{dr}=\underline{\underline{v}} \cdot \underline{-}-\mathrm{c} .
$$

To find the equation of sotica sor $e^{2}$, eac to verify our concept of "corpuscie emergy," we tilnt-

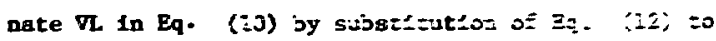
obtain

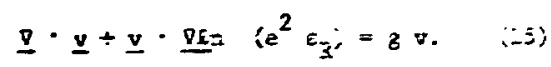

Agatn using the derivazive d/dt the divergence theorer for a $5 \mathrm{Eall}$ voli=e $V$,

$$
v^{-Z} \mathbf{d} \nabla / \dot{a} \tau=\underline{\nabla} \cdot \underline{v} .
$$

we obtain

$$
d \ln \left(e^{2} \varepsilon_{R} V\right) / A t=8 v \text {. }
$$

By definiog the trajectory iength $s=\int_{0}^{T} v d z$ this equation may be put into ine tamiliar for

$$
e^{2} \epsilon_{R} y=\left(e^{2} \varepsilon_{R} v\right)_{s=0} \exp \int_{0}^{6} g d s .
$$

The quantity $e=e^{2} \varepsilon_{a}$ is proporitonal to the energy contained in the small volume $v$. As expected, this quantity increases according to the intensity gain coefficlent $g$, verifying the assignent in Eq - (8) and justifying our concept of corpuscle energy or "welght" $e$.

He must now reassemble our frequency compoments in order to describe the time deperdent pulse. In the monochromatic pulse described atove we determined the optical length $L(s, w)$ so that the timedependent fleld is described by

$$
\underline{E}(s, t)=\int \underline{e}(s, \omega) \cos \left[k_{0} L(s, \omega)-\omega t\right] d \omega .
$$

Here $e(s, w)$ is centered on frequeacy $\omega_{c}$ and has bandwidth $\Delta w$ All of the frequencles within the banduldth produce nearly the same value of $L(6, \omega)$ so that we may use a linear approximation

where

$$
I(s, w)=L_{0}(s)+w L_{1}(s),
$$

$$
L_{I}(s)=(\partial L / \partial \omega) \omega=\omega_{0},
$$


and thus

$\underline{E}(s, t)-\operatorname{Re}\left\{\exp \left[1 k_{0} L_{0}(s)\right] \int \underline{e}(8, \omega) x\right.$ $\left.\exp \left\{1 \omega\left[k_{0} L_{1}(s)-t\right]\right\}^{0} d \omega\right\}$.

Now assuming that the gain $G(8)=\int_{0}^{\beta} 8 \mathrm{ds}$ is independent of $w$ over tha pulse banfulth we have frow Eq. (18)

$$
\begin{aligned}
& =e(0, w) .\left[V(0, w) \varepsilon_{R}(0, w) / V(s, w) \varepsilon_{R}(s, w)\right]^{1 / 2} \\
& \times[\exp G(s) / 2] \text {. }
\end{aligned}
$$

where we have exhlbited the explicit dependence of $V$ and $\varepsilon_{R}$ on path length and frequency. The mafor $w$ dependence of the right-hand side is in e $(0, w)$; over Its banduldth, the expression in the square root 1s essentially constant and may be replaced by Its value at $\omega_{0}$. Hence by defining the renaining integral to be $P$ we have

$$
\begin{aligned}
& \underline{E}(s, t)=\operatorname{Re}\left\{\exp \left(1 k_{0} L_{0}(s)+G(s) / 2\right) P\left(k_{0} L_{1}(s)-t\right)\right. \\
& x\left[v\left(0, \omega_{0}\right) \in\left(0, \omega_{0}\right) f\left(v\left(8, \omega_{0}\right) \in\left(s, \omega_{0}\right)\right] 1 / 2\right\} \cdot(23)
\end{aligned}
$$

This is a pulse whose portion at $s=0, t=0$ arrives at $g$ at $t$ ime $t$ given by

$$
k_{0} L_{1}(s) \sim t .
$$

The group velocity $v_{g}$ is $d s / d t$, and using Eq. (24), it is given simply by

$$
\begin{aligned}
v_{B} & =d s / d t=\left[\partial^{2} k_{0} L / \partial \omega \partial s\right]^{-1} \\
& =\left[\partial\left(k_{0} \mid v L /\right) / \partial \omega\right]^{-1}=[\partial k / \partial \omega]^{-1} \\
& =v\left[1+1 / 2 \omega \varepsilon_{R}^{-1} \partial \varepsilon_{R} / \partial \omega\right] .
\end{aligned}
$$

The significance of this result is that the corpuscles must be advanced with the group velocity rather than the phase veloc1ty. When there is no dispersion, Eq. (13) represents the acceleration of the corpuscles. When dispersion is present, we may use Eqs. (25) and (13) to find the corpuscle. speed from the phase speed.

\section{FIRST APPLICATION}

Our firgt application concerns tne nonilnear propagation of an intense pulse through an lonizable nedium. The medium 18 lonized instde and behind the pulse, but not ahead or to the side of $1 t$. In consequence the sedium refracts the pulse in the unfocusing sense, as if a number of negative lenses were traveling vith the pulse. The total refraction ay be significant, even if the change in refractive index is small because the "lens" is steady in the pulse frane. The problem is nonIinear because the fractional lonization is the time Integral of a rate which depends upon the pulse Intensity.

The motivation for this problem vas the transport of pulses through the 11thium vapor base pressure in a laser-fusion power reactor. 7 The results show that the allowed base pressure is much less than previously thought 8 The probleo is easily visualized from the coordinates Indicated in F1g. 1.

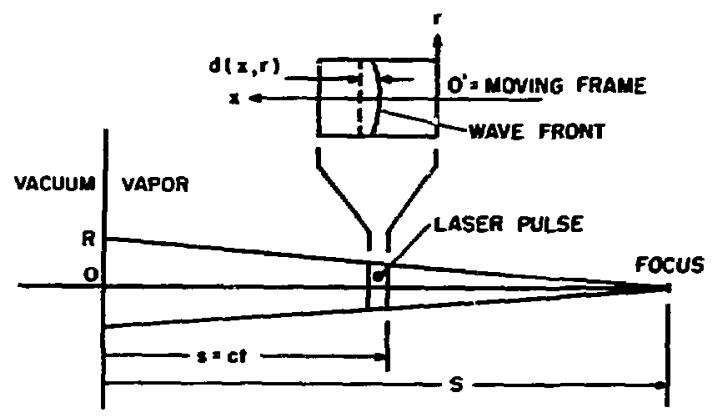

F1g. I Coordinate system Indicating the problem.

A plot of corpuscle weights (the tiny numbers on a relative scale of 0 to 9$)^{9}$ locations (at the tiny numbers), and directions (small vectors pointing ahead) is shown in F18. 2. The a priozi (vacuum) focus of the pulse is indicated by the arrow. The vectors in this low density case may be seen to point toward It. A similar plot in Fig. 3 for a higher density shows that many of the corpuscles are now "focused" further dow stream, giving an aberration which cannot be corrected by any element which a function of radius alone. 


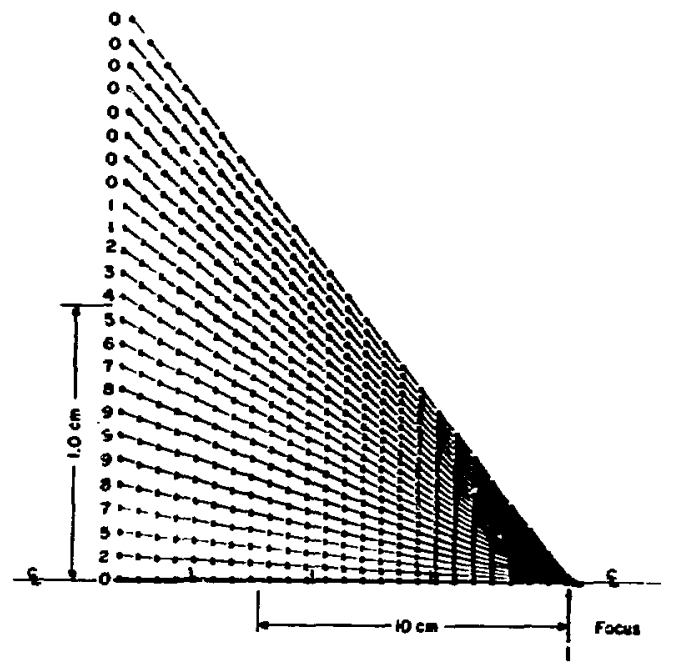

F1g. 2. Corpuscle plot for low density case.

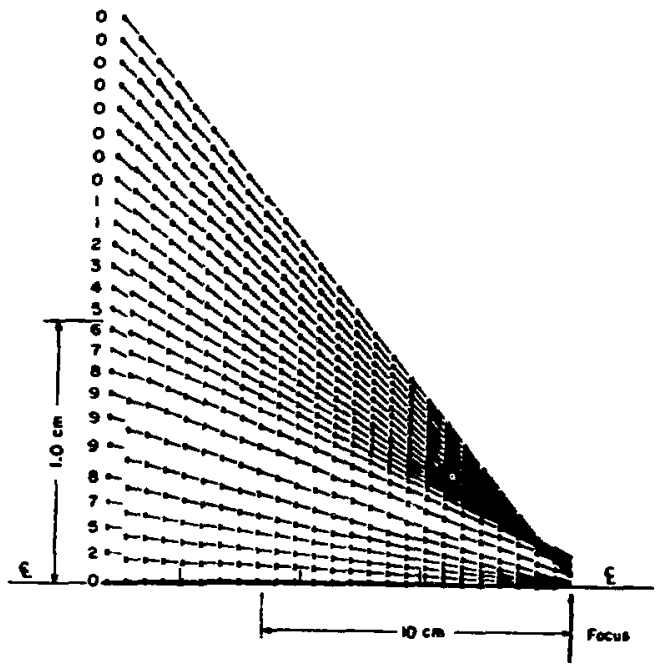

F1g. 3. Corpuscle plot for moderate density case.

A more severe case, corresponding to the conditions originally chosen for the fusion-reactor: ${ }^{7}$ is show to be extremely "unfocused" in Fig. 4. The extreme effect (large refraction of some corpuscles) required use of our nes method rather than existing ones.

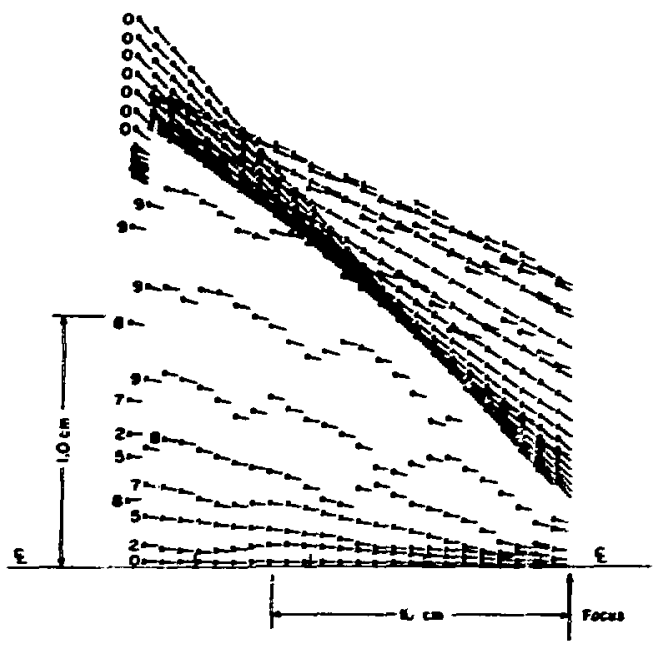

F1g. 4. Corpuscle plot for more severe cise.

\section{v. SECOND APPLICATION}

Our second application was the propegation of 11ght through the $1 \mathrm{~kJ}$ Los Alamos Nd: glass laser system, 10 in vere particularly concerned about the pulse's behavior in and beyond a disk amplifier. From the sketch in Fig. 5, we see this problem to be three-dimenstonal and to require the guneralfty of the CIM method.

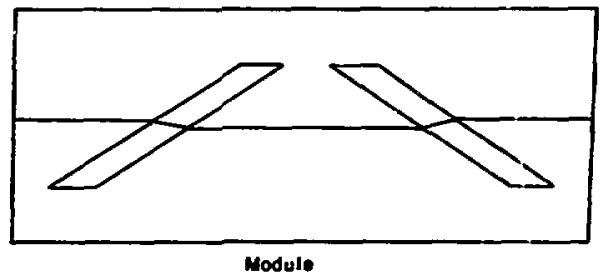

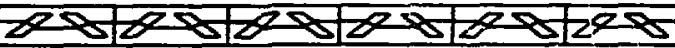

Nodular amplitier

F18. 5. Diagramatic reprecintation of a nodule consisting of two disks and the modular atplifier consisting of six modules. 
The large ocale effects to be stud:ed include: (1) wandering of the beam relative to the sominal axis and wandering or altering of parts of the beas relative to each other as functions of the intengity and specifled manufacturing tolexances, (2) gross self-focusits of the whole beam or parts of the beam (3) nonuniform anplifter cain puping aad gain saturation, (4) self-consistent combinations of effecta. While the CIM wethod lacks oufficlent reoolution to study sma11 scale oelf-focusing, the results from stability treatmeni ${ }^{11,12}$ can be parameterized and included as a prescription on intensity, gain, and disk thichness and spacing. By use of this code, amplifier design may consider self-focusIng, apertu:e filling fractions, aligment dif.tculties, and costs.

The computation following a swarm of corpuscles proceeds as outlined above. In the afr spaces the propagation is linesr and computer time is saved by crossing these gaps in one step. Refraction at the surface is discontinuous and is accouplished with a Snell's law subroutine including the nonlinear index.

For propagation in a nonlinear medium pulse, Information is stored on a series of planes whose separation is sufficlently small to perit a linearization of the problem between planes. The Intensity between planes depends on the corpuscle's direction and position as given by

$$
I(x, y, z, t)=I_{s}\left(x_{, j}^{\prime}, t-s / v-t_{b}\left(x^{\prime}, y^{\prime}\right)\right),
$$

where $I_{s}(x, y, t)$ is the Intensity on the surface of the previlous plane in terms of the two transverse coordinates $x$ and $y$ and the time $t$. Also $x$ and $y$ are the locations on the surface of the projection of $x, y, z$ back along the trafectory which is a distance $s$ to the surface, and $t_{b}$ is a function introduced for convenience.

Sepa rate computer subroutines which correspond to many experimental device elements such as aper. tures, lenses, telescopes and also to the many dtagnostic apparatus such as calorimeters, or time or space resolved detectors of besm intensity. There are other craputer dfagnosticy which have no direct experfmental anelogue as yet such as a "time resolved bura pattern" giving a spacially and tempo- rally resolved intensity distribution. There is also a subroutine to rctate the bead relative to the Cartesian wesh in order to test to see if a sufficient number of corpuscles per cell have been set up Inttally. Figure 6 shous the 11luminance of the pulse as a function of the two transverse coordinatea, as originally oet up.

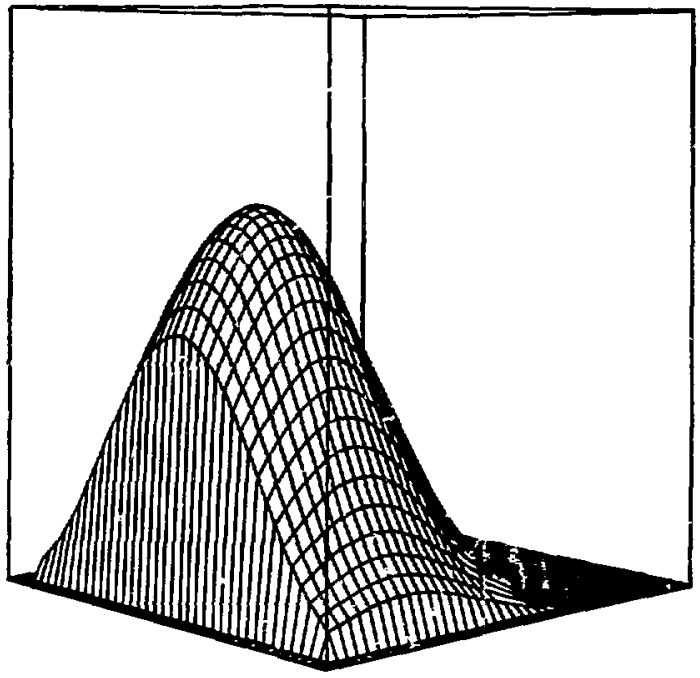

F18. 6. Pulse 11luminance $\left(\mathrm{J} / \mathrm{cm}^{2}\right)$ is the helght and the coordinates perpendicular to the propagation direction form the plane of the base. This is a test pulse uth one particle per cell.

Figure 7 shows the same pulse rotated $45^{\circ}$ when each cell contains but one corpusele. Figures 8 and 9 show that this Intolerable pulse nolse is substantally reduced by using 4 and 16 corpuscles per cell, repectively.

A large number of data-card cowwands, each with arguments to control the propagation of the pulse, are avallable. Five commands are utllized for setting up the pulse. A SURFACE command advances the pulse from one surface to the next. A command changes the medla by application of Snell's law. Other cormands give the diagnostics described above. This method of using serial commands to control the propagation gives the method added flexibility and simplicity and allows preprosessing of the commands to check for errors which vould ordinarily cause a computation to abort in the middle. 


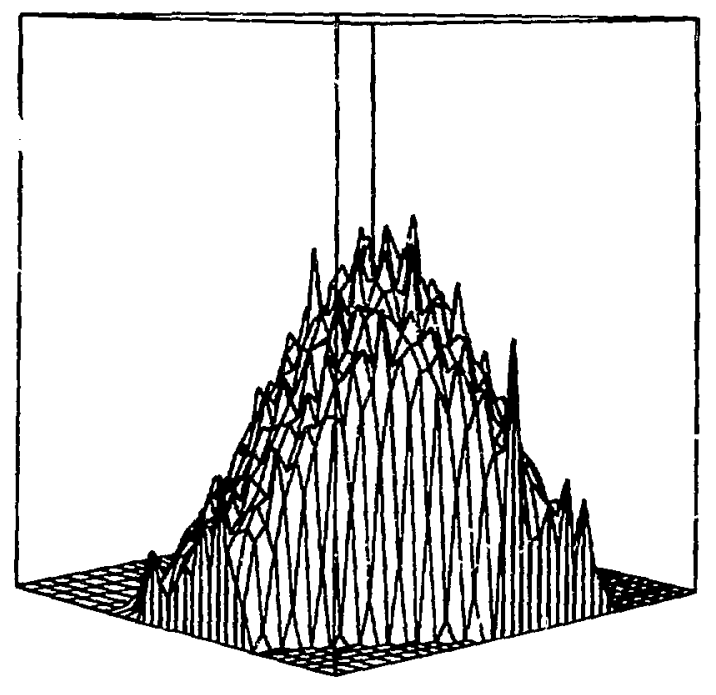

F1g. 7. Same as Fig. 6 but the pulse has been rotated $45^{\circ}$ which Intraduces numerical noise.

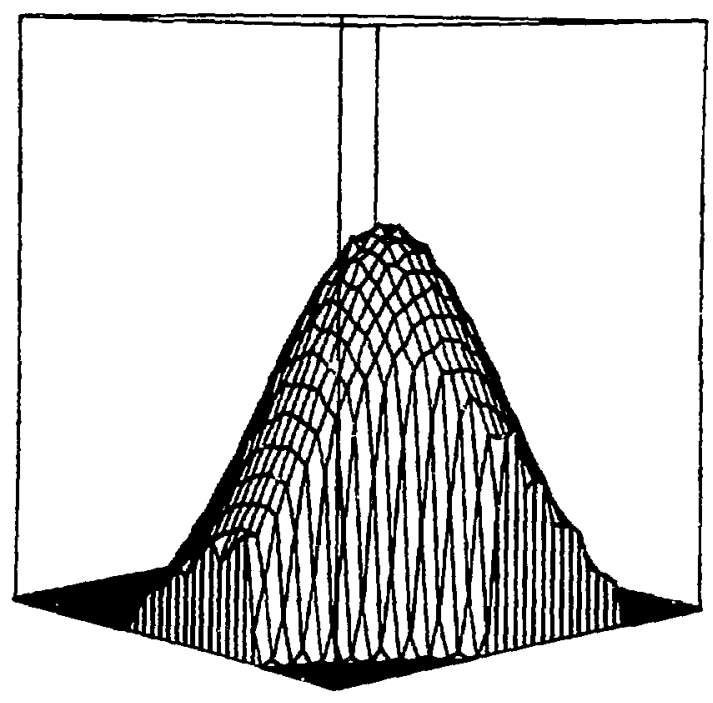

F1g. 8. Same as F1g. 7 but with four particles per cell.

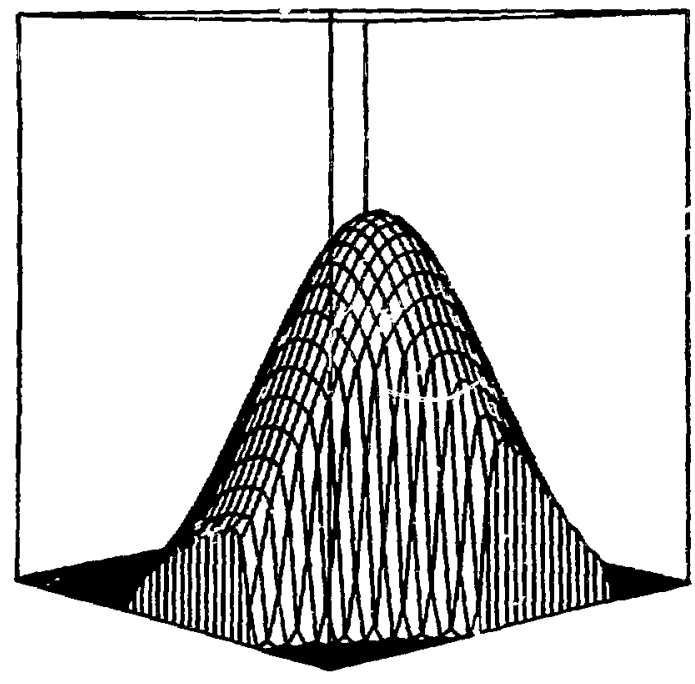

F13. 9. jame as F1g. 8 but with 16 particles per cell.

The data card commands, thenselves, are groduced by Input preprocessing which inserts specified manufacturing tolerances at random Into the data card arguments.

Propagation of a $10 \mathrm{~J}, 400$ ps (full widh at half maximum) pulse through a 12-disk amplifier is shrin in Figs. $10-15$. The original spactal dependence (Airy-profile) of the pulse is that shown In Fig. 10, the clear aperture being $3.6 \mathrm{~cm}$. The original gaussian time dependence 15 shown in F1g. 11. Manufacturing tolerances of \pm 40 min were assumed (abnormally large) for the parallelism of faces of $a$ disk and the disks were assumed to be aligned \pm 40 min relative to the nominal axis. Since random tolerances are used, the errors tend to cancel one another so that the vorst amplitude distortion of the pulse may come anywhere in the ampl1fier. Figure 12 shows the distortion of this pulse when exiting the last disk, at 20 ps before the peak intensity of the pulse has arrived (the peak has shifted forward 50 ps due to saturation). Upon exiting the amplifier the pulse has $63 \mathrm{~J}$.

The pulse 1llumance as It exics the amplifier is shown in Figs. 13 and 14 as a function of the transverse coordinates and this shows relatively 
little distortion compared to the distortion asen In Fig. 15 in which the pulse has run out beyond the emplifier $18.8 \mathrm{~m}$ in alr.

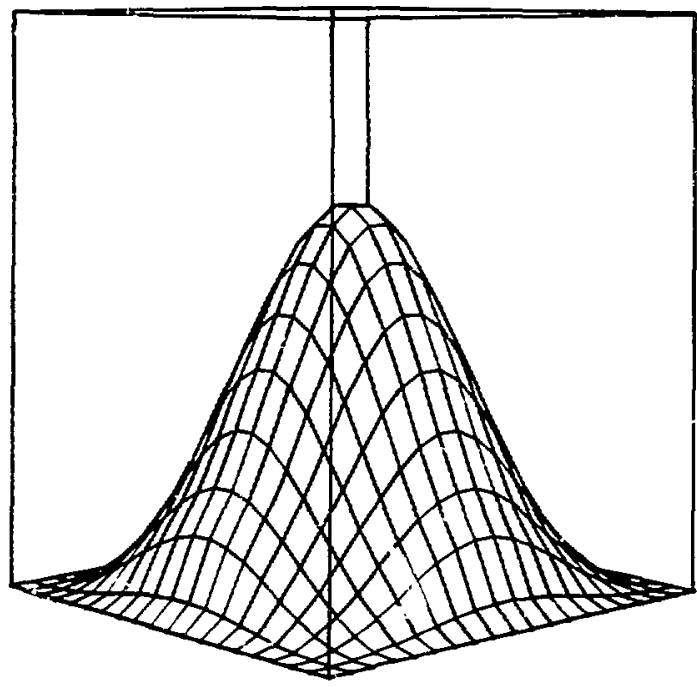

F1g. 10. Pulge 1!luminance $\left(\mathrm{J} / \mathrm{cm}^{2}\right)$ of a $10 \mathrm{~J} \mathrm{Alry-}$ profile pulse in a squareperture of 3.6 $\mathrm{cm} \times 3.6 \mathrm{~cm}$.

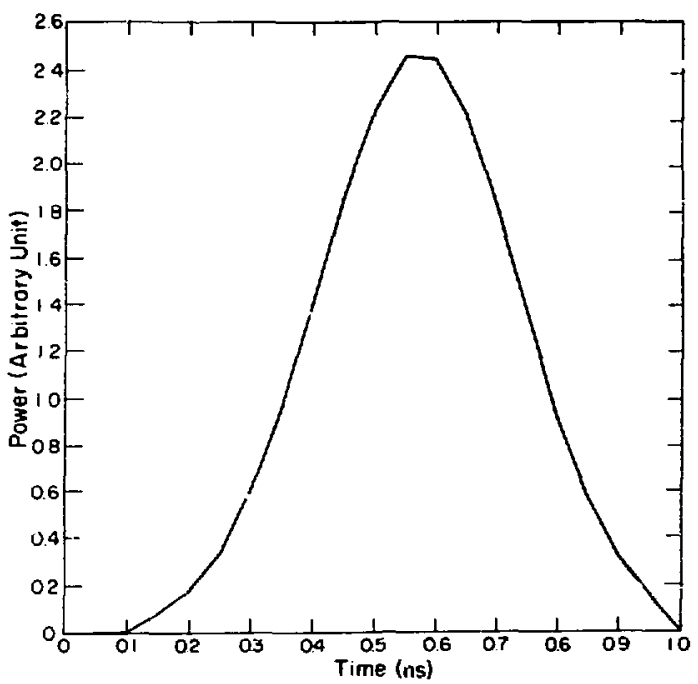

F1g. 11. Gaussian time dependence of a $10 \mathrm{~J}$ Alryprofile pulse. The 11ne segments are indicative of the numerical approximation.

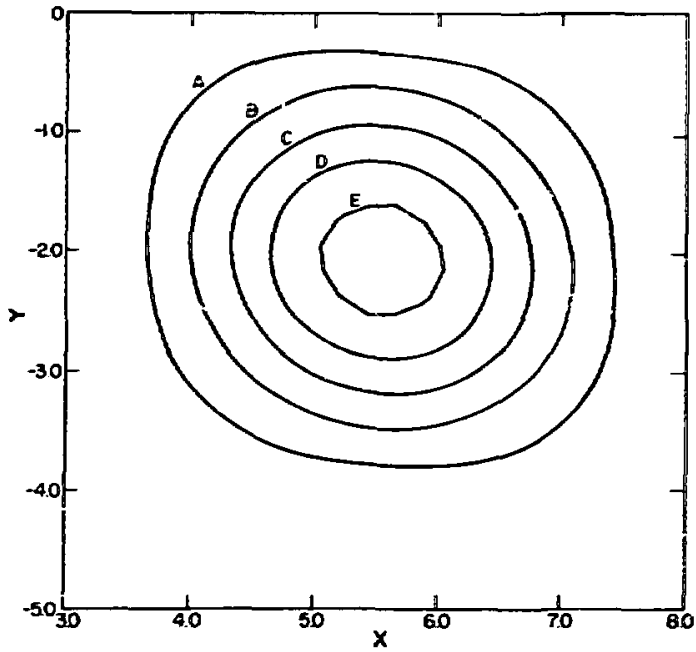

F18. 12. A contour plot of pulse intensity 20 ps before the peak Intensity as the pulse exits the last disk. The contours $A, B, C, D$, and $E$ are 10\%, 30\%, 50\%, 70\%, and $90 \%$ of peak, respectively. The lack of true parallelism of the disk faces accounts for the position of the peak of the pulse.

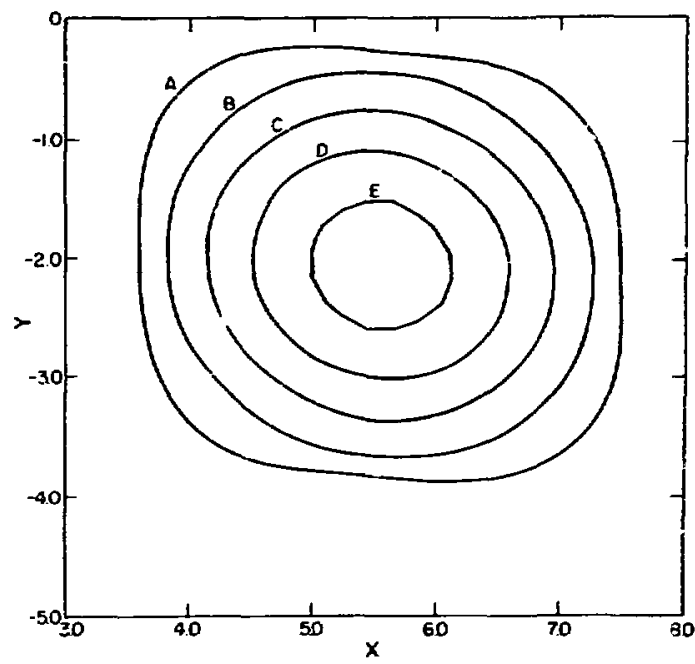

F18. 13, A confout piot of the pulse 1lluminance $\left(J / \mathrm{cm}^{2}\right)$ as the pulse exits the last disk. The contours $A, B, C, D$, and $E$ are $10 \%, 30 \%$, $50 \%, 70 \pi$, and $90 \%$ of peak. 


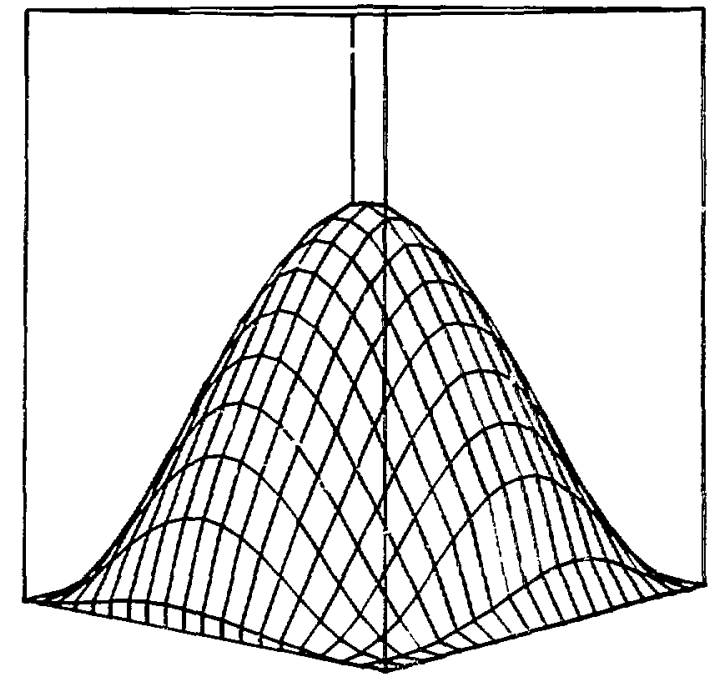

F18. 14. A 3-D projection showing the same pulse as in F1g. 13.

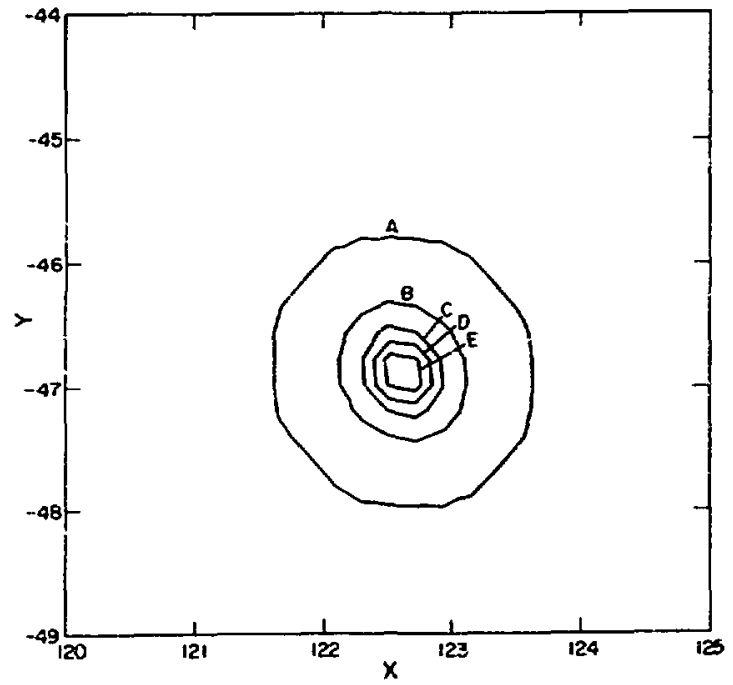

Fig. 15. A contour plot of the pulse 111 uminance in which the pulse has run out $18.8 \mathrm{~m}$ beyond the anplifier in air. Note the decrease in diameter of the pulse. Same convention as is F18. 12.
At 18.8 a can-out the distortion of the pulse is ast severe at 1 to peak intengity as 10 ghom in Figs. 16 and 17 . Bg coparing Figs. 14, 16 . and 17 ve can see that the cealfal portios of the pulse is converging vhile che beztaning and ead of the pulse converbe unch zore vealcly. Thws, a different leas 18 required ro focus the zost intense part of the pulse than is reguired for the rest. Pinally, the tife dependence of the prolse at $18.8=$ rum-out 15 show in Fig. 18 ; this 11 quite close to shat one sould expect uthout spakfal distortion.

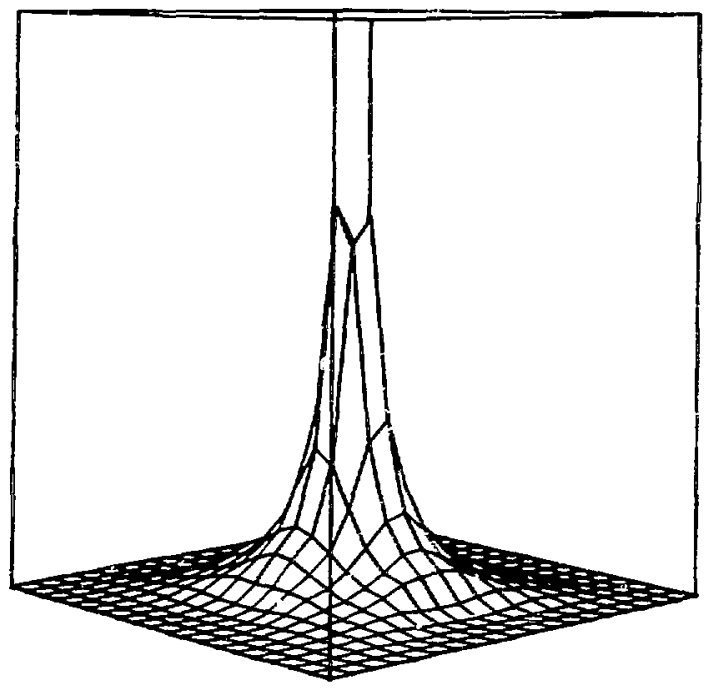

Fig. 16. A 3-D profection shcaing the pulse intensity at the peak Intensity 18. 8 a beyond the amplifier. 


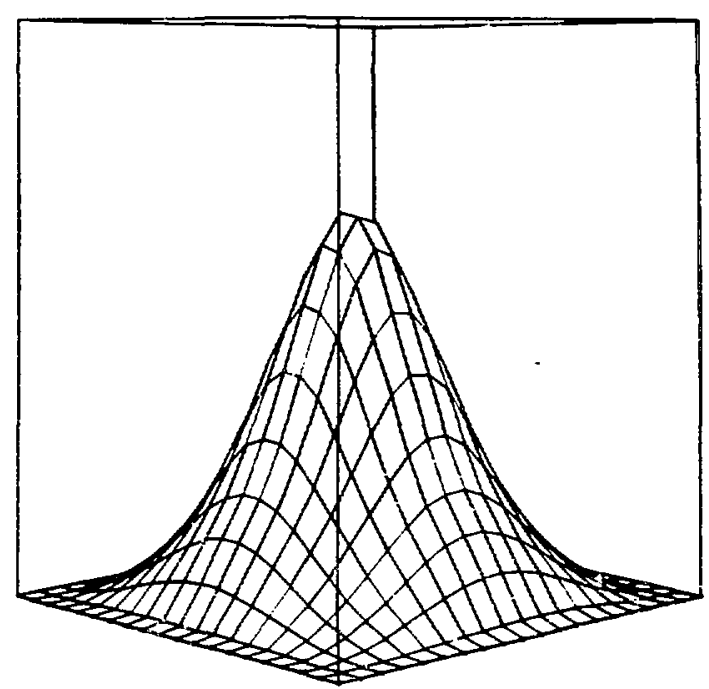

Tig. 17. A 3-D profection showing the pulse intensity rar the beginning of the pulse 18.8 in beyond the amplifier end.

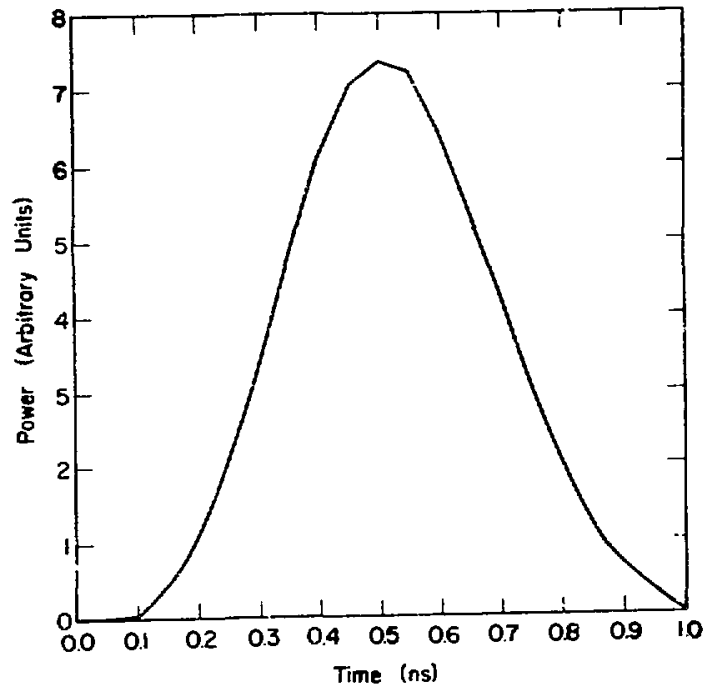

F1g. 18. The time dependence of the pulse at $18.8 \mathrm{~m}$ beyond the amplifier end. There is a slight forvard shift of the peak due to saturation as one would expect.
REPERENCES :

1. 6. R. Suydan, "A Liser Pulse Propagation Cocie," Los Alas Scientific Laboratory report LA-5607MS (1974).

2. F. H. Harlov, "The Particle-1n-Cell cosputing Method for Pluld Dynamics," in Methods in Compt. Phys., B. Adler, S. Fermbach, H. Rotenberg, Eds., Acadealc Press 3, 319 (1964).

3. R. L. Morse, "Maltidirengional Plaswa Simulation by the Parcicle-In-Cell Method," In Mechods in Compt. Phys., A. Siron and H. B. Thoupson, Eds., Acadenle Press 9, 213 (1970).

4. Uur use of the term corpuscle is consistent with Newton's definition of a "ray," but the tipe independent notion of streamines seens to be prevalent in godem discussion of rays.

5. This result also follows directly from $\mathrm{Eq} .3 .1$ (16) of the following reference having similar notation: M. Born and $Z$. Wolf Principles of Optics Th1rd (Revised) Edition (Pergamon Press, N.Y.), 1965.

6. D. B. Henderson, "Laser Puise Propagation Through Ionizable Media," Los Alamos Sclentific Laboratory report LA-5086-HS (1972).

7. L. A. Booth, Compller, "Central Station Power Generation by Laser-Drived Pusion," Los Alamos Scientific Laboratory report LA-4858-45, also published in Nucl. Eng. Design 24, 263 (1973).

8. D. B. Fenderson "Pulse Unfocusing within LaserFusion Reactors," Nucl. Eng. Design (to be published).

9. This is an axisymetric problem and the weights shown are a radius factor; hence the "zero" meaning from $0 z$ up to $10 z$ of the caximtin appears near the or 1 gin as well as the edge of the Inithal gausstan pulae.

10. D. H. G111, R. C. Hyer, P. N. Mace, J. McLeod, J. E. Perry, C. B. Reed, R. H. Robertson, N. J. Terre11, and B. E. Watt, "A High Power Nd: Glass Laser System for Pusion Research," VIII Internationis Quantum Electronics Conference (1974).

11. B. R. Suydam, "Self Focusing of Fery Powerful Laser Beams," in Laser-Induced Damage in Opt1cal Materials: 1973, Natl. Bureai Spec. Pub1. No. 387 (U.S. GPO, washington, D.C., 1973).

12. C. James Elliott, "Gain Saturation and SelfFocusing Considerations in the Destgn of Optical Ampliflers," App1. Letter 24, 91, (1974). 